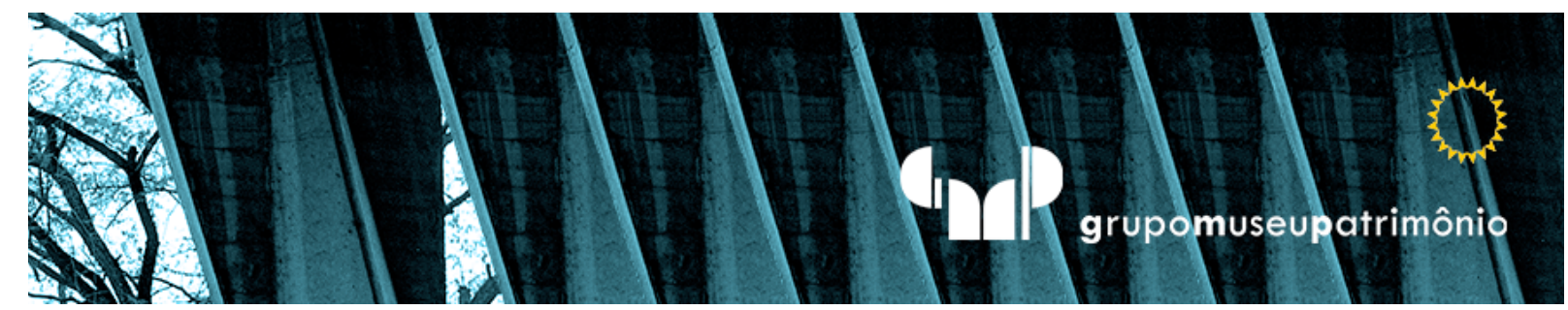

\title{
A representação da ausência nos vestígios de ação
}

\author{
The representation of absence in the \\ actions traces
}

\section{La representacion de la ausencia en los vestígios de acción}

Allan Tanioka Yzumizawa

PPGAV-Unicamp, Campinas, Brasil.allanyzumizawa@gmail.com 


\section{Resumo}

Partindo das questões sobre arte e política e da potência das imagens colocadas por Jacques Rancière e Georges Didi-Huberman, o presente artigo propõe a discussão sobre as formas de representação da ausência a partir de trabalhos entendidos como vestígios de ação. Esses trabalhos, ao invés de trazer a imagem representada do corpo, a partir de seus vestígios, denunciam a sua ausência, trazendo à discussão sobre formas de articular o visível.

Palavras-Chave: Arte e política. Vestígio. Ausência. Vestígio de ação. Partilha do sensível.

\section{Resumen}

A partir de las preguntas sobre arte y política y el poder de las imágenes planteadas por Jacques Rancière y Georges Didi-Huberman, este artículo propone una discusión sobre las formas de representar la ausencia desde obras entendidas como vestigios de acción. Estas obras, en lugar de traer la imagen representada del cuerpo, a partir de sus huellas, denuncian su ausencia, trayendo a la discusión sobre formas de articular lo visible.

Palabras-Clave: Arte y política. Vestigio. Ausencia. Vestigio de acción. Reparto de lo sensible

\section{Abstract}

Starting from the questions about art and politics and the power of images placed by Jacques Rancière and Georges Didi-Huberman, this article proposes a discussion on the forms of representing the absence from artworks understood as trace of action. These works, instead of bringing the represented image of the body, from its traces, denounce its absence, bringing to the discussion about ways of articulating the visible.

Keywords: Art and politics. Traces. Absence. Trace of action. Distribution of sensible. 


\title{
AS RELAÇÕES ENTRE ARTE E POLÍTICA
}

\author{
A imagem é a um só tempo uma substituição metafórica, \\ uma ilusão de presença, e, justamente por isso, \\ uma metonímia, um signo de uma ausência e perda.
}

(BHABHA, Homi. 2013, p.95)

\begin{abstract}
D iante de uma inundação, proliferação e consumo de imagens, a questão referente ao local que se encontra a sua potência, nunca deixa de ser um elemento de reflexão e de extrema importância nos debates na arte contemporânea. Tomamos emprestada, portanto, a indagação de Jacques Rancière: "sob que condições é possível declarar certos acontecimentos irrepresentáveis?" (RANClÈRE, 2012, p.119) Sob que condições pode se constituir uma imagem irrepresentável, uma imagem que declare ou denuncie uma ausência, uma perda? Quais são os acontecimentos, as formas, os signos que se entendem como irrepresentáveis, ou tornam a situação ao ponto de garantir uma fuga de uma certa representação? O que me interessa portanto, é quando o aspecto de uma figura representada, escapa ou não encontra um representante que dê conta de trazê-la visualmente, na tentativa errante de traçar os rastros de um irrepresentável.
\end{abstract}


Talvez o mostrar demais - o excesso de representação - é responsável em esgotar a potência da imagem a partir de seu exagero, e que de alguma forma, tornou-se um modus operandi de vários/as artistas visuais na produção de trabalhos dos quais anseiam uma mudança política. No livro $O$ espectador emancipado (2012b), Jacques Racière, descreve ironicamente as formas de como alguns trabalhos de arte encaram sua forma política:

Alguns artistas transformam em estátuas monumentais os ícones midiáticos e publicitários para nos fazerem tomar consciência do poder desses ícones sobre a nossa percepção; outros enterram silenciosamente monumentos invisíveis dedicados aos horrores do século; uns se empenham em mostrar-nos os "vieses" da representação dominante das identidades subalternas, outros nos propõe afinar o olhar diante das imagens de personagens com identidade flutuante ou indecifrável. (2012b, p. 52)

Contudo, essa diversidade de estratégias não só traz uma multiplicidade de manifestações como também a incerteza quanto à configuração do território no qual a política atravessa ou tangencia a arte. Ao observar os trabalhos que configuram o vasto campo das relações praticadas entre arte e política, notamos a recorrência do modelo comum de eficácia: mostrar os estigmas de dominação social, os conflitos de opressão, ridicularizar os ícones midiáticos, ou seja, uma lógica representativa - ou como Rancière menciona no seu livro $A$ partilha do sensivel (2009) uma lógica do regime mimético (RANCIÈRE, 2009, p. 30). Esse modelo de eficácia, referente ao regime mimético das artes, remete ao século XVIII, no qual se concebia uma continuidade e manutenção das relações entre as formas sensíveis produzidas pela arte com seus respectivos observadores, que eram afetados por essas formas (RANCIÈRE, 2012b, p. 53). Nesse modelo, muito fomentado pela atmosfera das Academias de Arte, a mímese não significava a representação ou a imitação de uma forma da natureza, mas a estruturação de normatividades que conservariam formas sensíveis e identificáveis como arte (RANCIÈRE, 2009, p. 30-31). Dentro dessa lógica criticada por Rancière, os trabalhos de arte de cunho político ousam assumir uma postura esclarecedora e representativa dos estigmas das forças opressoras do capital e das elites institucionais, utilizando-se das estratégias 
descritas acima. Para o filósofo, esse modelo persiste curiosamente no território das artes visuais atuais:

Sem dúvida já não acreditamos na correção dos costumes pelo teatro. Mas ainda gostamos de acreditar que a representação de resina deste ou daquele ídolo publicitário nos erguerá contra o império midiático do espetáculo ou que uma série fotográfica sobre a representação dos colonizados pelo colonizador nos ajudará a escapar hoje das ciladas da representação dominante das identidades. (2012b, p.54)

Essa descrença empregada pelo filósofo frente ao regime mimético, não anuncia uma prática imperfeita do/a artista, ou uma defasagem ao construir uma proposição que comunique com o/a espectador/a. Tratando-se de um aprofundamento da análise dentro do que se articula internamente e externamente o trabalho artístico. Para Rancière, o problema portanto, se encontra na própria fórmula, na pressuposição de um continuum sensível entre a produção de imagens, gestos ou palavras e a percepção de uma situação que empenhe pensamentos, sentimentos e ações dos espectadores. (RANCIÈRE, 2009, p. 54) Portanto a arte, para o filósofo, não se trata apenas em transmitir conteúdos de comunicação, mas que sua potência esteja nas suas articulações disjuntivas quando essa entra em contato com uma pessoa espectadora. Existe portanto uma desconfiança na eficácia dentro desse modelo mimético do regime da arte, no que confere às mudanças e engajamentos de corpos que absorvem esses trabalhos. Para Rancière, a lógica da continuidade que estabelece um acordo da forma sensível com o observador mantém certo consenso de manutenção de uma partilha sensível. Desse modo, o problema então, não se refere à validade moral ou política da mensagem transmitida pelo dispositivo representativo. Refere-se ao próprio dispositivo. Sua fissura põe à mostra que a eficácia da arte não consiste em transmitir mensagens, dar modelos ou contramodelos de comportamento ou ensinar a decifrar as representações. "Ela consiste sobretudo em disposições de corpos, em recorte de espaços e tempos singulares que definem maneiras de ser, juntos ou separados, na frente ou no meio, dentro ou fora, perto ou longe." (RANCIÈRE, 2009, p. 55). O que fica em questão dentro das perspectivas apontadas por Rancière, distancia as relações das mensagens 
propriamente políticas, se atentando a seus recortes e formas de articulações que se organizarão dentro de uma outra lógica de eficácia.

Existe portanto, para Rancière, uma estética na política que se ocupa do que se vê, do que se pode dizer sobre o que é visto, de quem tem competência para ver e qualidade para dizer; quem possui o discurso ou quem é silenciado; quem tem o direito e quem não o tem (RANCIÈRE, 2009, p. 15). É nesse sentido que o filósofo quer tratar as relações entre estética e política: por meio da reestruturação da partilha do sensível, ou seja, reconfigurando as formas de perceber, em tornar visível quem é invisível ou tornar compreensível o discurso de quem é silenciado. Para ele, se existe um espaço de mudança, esse se encontra no âmbito do sensível, e não dentro de uma estrutura racional e lógica, o qual manteria uma relação consensual.

Entendendo essas questões, podemos retornar ao ponto da imagem irrepresentável. Seria essa, portanto, uma imagem que escapa das relações do comum? Seria um ponto de disjunção responsável em trazer fissuras nesse tecido sensível ao correlacionar o que não estava antes relacionado, ou de tornar a presença de algo que somos incapazes de ver? A imagem irrepresentável, trata-se de uma imagem de perda, porém é a partir dessa perda que se torna viável o ato de enxergar.

A partir da descontinuidade ou do que podemos entender pelo dissenso provocado pela particularidade do regime estético, é que a arte pode tangenciar a política. Sendo, desse modo, uma atividade que reconfigura os âmbitos sensíveis nos quais se definem objetos comuns partilhados. A potência da descontinuidade estética, atenta para a imagem que seja suspensa, que não apresenta uma continuidade entre forma com seu receptor, mas uma abertura, um hiato. Algo que podemos notar, por exemplo no trabalho de Clara lanni, Natureza Morta ou estudo para Ponto de Fuga (2011). Nele, a artista dispõe de 9 chapas de aço com perfurações de tiros de 
munições usadas pela polícia de cada cidade onde esse trabalho é exposto ${ }^{1}$. Clara lanni, portanto, abdica em mostrar a violência do corpo baleado pela Polícia Militar, e tensiona o nosso olhar para as munições que matam (perfuram) esses corpos. As chapas de aço dispostas lado a lado, acabam dialogando com as formas geométricas e seriadas da arte minimalista, porém adentrando uma verticalidade de interpretações sugeridas por meio das perfurações causadas pelas munições: a presentificação de uma violência policial dos quais muitos não testemunham. Logo, essas chapas presentificam no espaço, um vestígio de ação o qual aponta para um corpo que não está mais presente, abdicando da forma de representação figurativa do indivíduo que recebe a violência.

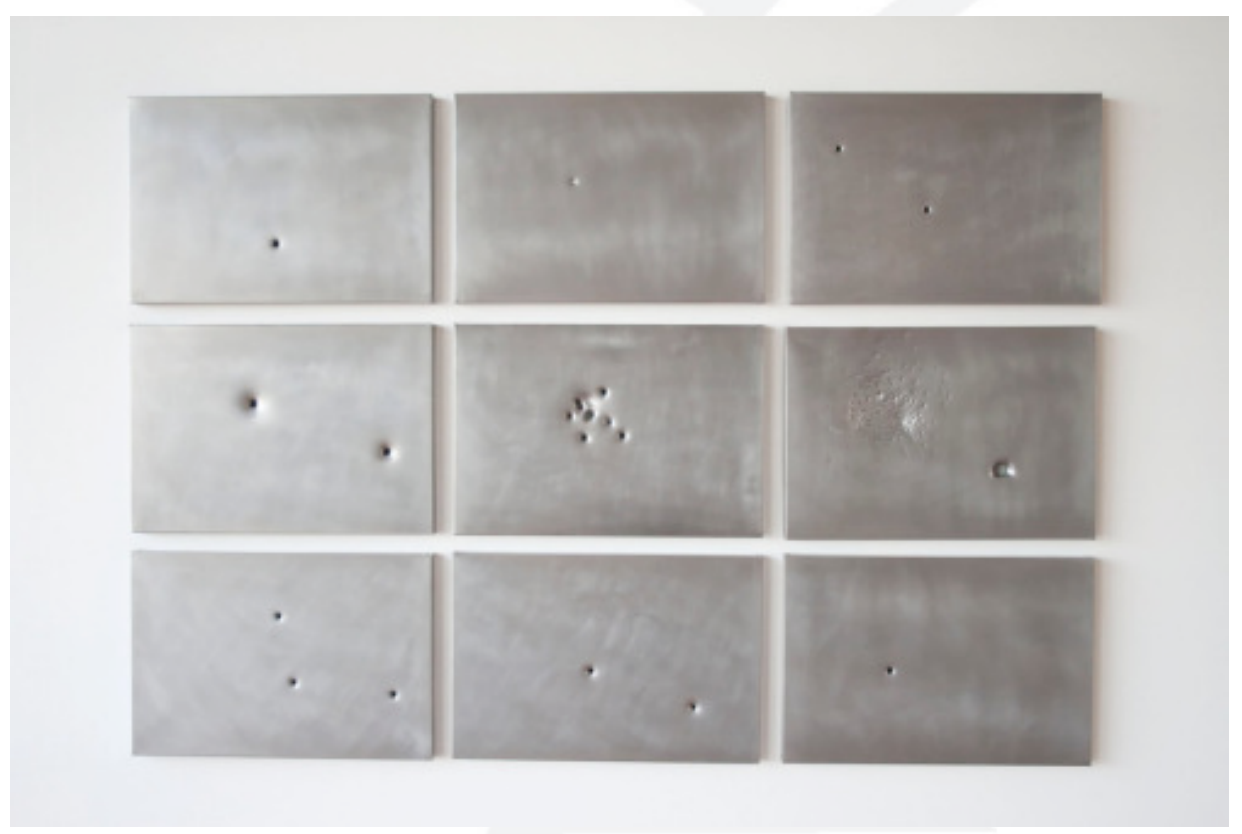

Figura 1: Clara lanni. Natureza morta ou estudos para ponto de fuga. Fonte: Site pessoal da artista.

\footnotetext{
1 "Natureza Morta ou estudo para Ponto de Fuga" (2011) já foi realizado no contexto das cidades de São Paulo, Belo Horizonte e Berlim. Em cada uma delas, os calibres das munições variam de diâmetro, o que nos faz refletir sobre o modo de como a polícia exerce sua violência, bem como os modos de acordo de venda e de tecnologia militar.
} 
Portanto, a experiência do dissenso vai em oposição às adaptações conservadoras do regime mimético, assim, as produções artísticas se dissociam dos modos de percepções comuns. O dissenso, é capaz de indicar novas referências entre o que é visível e enunciável, mostrar o que não era facilmente visto, correlacionar o que não estava correlacionado com o objetivo de criar rupturas no tecido sensível das percepções e na dinâmica dos afetos (RANCIÈRE, 2012b, p. 64). Nesse sentido:

Há uma estética da política no sentido de que os atos de subjetivação política redefinem o que é visível, o que se pode dizer dele e que sujeitos são capazes de fazê-lo. Há uma política da estética no sentido de que as novas formas de circulação da palavra, de exposição do visível e de produção dos afetos determinam capacidades novas, em ruptura com a antiga configuração do possível. (RANCIÈRE, 2012b, p. 63)

O regime estético da arte, entretanto, gera um certo paradoxo no que compreende as relações entre a continuidade e a descontinuidade. De acordo com o desejo de transformação social da/o artista, construir um trabalho dentro de uma lógica de articulação do regime estético, o dissenso acaba não Ihe garantindo uma direção que o espectador tomará. Isso porque o trabalho sendo descontínuo, esse se articula como um ponto disjuntivo, que acaba não Ihe entregando uma informação fechada, mas um ponto de interrogação, ampliando o leque de seu entendimento, tornando-se de alguma maneira, inesgotável por sua própria natureza. Desse modo, demanda-se um engajamento do espectador, que através de suas articulações próprias, modificará o seu entendimento sensível. Portanto, existe uma ansiedade precipitada pelo/a artista, para que o trabalho artístico efetive de fato alguma mensagem emancipadora e esclarecedora, em contraposição a sua efetividade em movimentar e engajar esse espectador. Talvez, seja a partir dessa ansiedade, que encontramos as resoluções tão didáticas de uma grande gama de trabalhos e manifestações artísticas. 


\section{O VESTÍGIO DE AÇÃo}

Falar de uma ausência, de um corpo que falta, seria falar de uma anti-imagem, ou de uma imagem que não existe, pois ela é faltante. Podemos então lançar a pergunta, de que se existe uma imagem irrepresentável (RANCIÈRE, 2012a). No primeiro momento parece ser inalcançável tal feito já que seus pressupostos paradoxais distanciam o representante (imagem) do representado (a ausência) (RANCIÈRE, 2012a, p.120). Talvez, aí, possamos relacionar precocemente um impoder ${ }^{2}$ da arte (RANCIÈRE, 2012a, p. 121) com as formas de dissenso próprias ao regime estético. A imagem faltante, a imagem de um corpo que não está presente, é potente por sua própria natureza de suspensão de acordo com as ideias trazidas anteriormente. Portanto, cabe perguntar e investigar as relações que articulam o que é chamado de vestígios de ação, partindo do entendimento das materialidades das quais são procedidas por uma ação e que suas marcas acabam apontando para o corpo que deixa de presentificar no espaço. Há portanto, uma dissociação entre o vestígio representante com o que é representado, já que somos incapazes de contatar o causador de sua origem. Portanto, a defasagem ou a suspensão do representado, trata-se de uma característica comum aos trabalhos de arte entendidos como vestigiais.

A paradoxalidade de constituir uma imagem do invisível, ou de um corpo que não está presente se confirma a partir da premissa de que o ato de ver, seja impreterivelmente um ato tautológico. Georges Didi-Huberman, discorrerá sobre a questão em seu livro $O$ que vemos, o que nos olha (2010). O filósofo nos propõe uma outra maneira de encarar o ver: "devemos fechar os olhos para ver quando o ato de ver nos remete, nos abre a um vazio que nos olha, nos concerne e, em certo sentido, nos constitui". (DIDI-HUBERMAN, 2010), p.31) Esse constituir, assemelha-se muito às ideias do dissenso dado pelo

\footnotetext{
2 Impouvoir em francês. A nota de tradução do livro de Jacques Rancière "O destino das imagens" (2012), menciona como um neologismo acadêmico francês de "não-poder" e não relaciona ao conceito "impoder" articulado por Antonin Artaud.
} 
regime estético das imagens anunciado por Rancière diante da perda ou da descontinuidade entre a forma visível e seu acordo de enunciação:

(...) então começamos a compreender que cada coisa a ver, por mais exposta, por mais neutra de aparência que seja, torna-se inelutável quando uma perda a suporta ainda que pelo viés de uma simples associação de ideias, mas constrangedora, ou de um jogo de linguagem -, e desse ponto nos olha, nos concerne, nos persegue. (DIDIHUBERMAN, 2010, p.33)

Para Didi-Huberman, o trabalho de arte, trata-se de uma obra de perda: "Abramos os olhos para experimentar o que não vemos, o que não mais veremos - ou melhor, para experimentar que o que não vemos com toda a evidência não obstante nos olha como uma obra de perda". (DIDI-HUBERMAN, 2010), p.34). O autor escreve sobre as evidências do túmulo, partindo de seu volume geométrico feito com uma massa de pedra trabalhada, tornando-se um volume indicado pelo vazio destinado ao corpo semelhante ao nosso, esvaziado de sua vida. Esse volume que nós olhamos, nos retorna o olhar com a ausência do corpo, ou do corpo que não está mais presente: "Seja como for, o homem de crença verá sempre alguma outra coisa além do que se vê, quando se encontra face a face com uma tumba" (DIDI-HUBERMAN, 2010, p.48).

É nesse sentido que encaramos para os vestígios de ação, ou para os traços e evidências em alguns objetos de arte. Esses objetos abdicam de uma presença corporal ou representativa, lançando-se a partir de sua própria perda. Ao mesmo tempo em que nega o corpo por meio de sua ausência, acaba trazendoo a partir dessa suspensão, como podemos notar no trabalho mencionado anteriormente de Clara lanni. Em Natureza Morta ou estudo para Ponto de Fuga (2011), as chapas de aço perfuradas com balas de munições da polícia não apresentam um corpo. Existe portanto, uma rejeição do antropomorfismo que ao contrário do que imaginamos, presentifica a forma humana por meio de sua própria perda. Mesmo abdicada de sua presença figurativa, existe um corpo composto pela articulação dessas formas geométricas metálicas perfuradas, um corpo que nos assombra e que ao mesmo tempo somos incapazes de vê-lo tautologicamente. É essa presença suspensa que Rancière e Didi-Huberman estão defendendo como potência na arte. 
No texto do catálogo da exposição Out of Actions (1998) ${ }^{3}$, a crítica e pesquisadora Kristine Stiles escreve sobre a relação da eliminação do antropomorfismo nos objetos de arte em favor do ganho do espaço-tempo e da presença do espectador. Ao mesmo tempo, a autora acaba concordando que mesmo esses ganhos trazidos pelo minimalismo, muitos artistas retornam a introduzir o corpo na materialidade sem que haja a perda desses elementos:

\begin{abstract}
Se foi a eliminação do antropomorfismo em favor de uma objetualidade obsoleta ou da presença material que permitiu que o minimalismo e a escultura ativassem a consciência do espectador de uma experiência que se desenrolava no espaço real e no tempo real, é importante observar como os artistas que trabalham desde então, reintroduziram referências ao corpo sem negar o impacto do objeto em seu ambiente físico. (STILES, 1998, p. 257, tradução nossa)
\end{abstract}

O que fica evidente diante dessas reflexões, é que os trabalhos de arte compreendidos como vestígios, possuem um jogo de presença-ausência, no qual um elemento é abdicado para que a presença do vestígio no espaço aponte para esse elemento que falta, para esse hiato. Em algumas situações, sua presença é tão precária e tão frágil, que beira ao desaparecimento. Situações visíveis de acordo com trabalhos que utilizam materiais frágeis como poeira, grãos, etc.

Muitos vestígios de ação, além de utilizar materiais frágeis, acabam relacionando a espacialidade do chão, devido ao esgotamento do potencial gravitacional e do potencial cinético exercido por uma ação. Essas relações podem ser encontradas nos trabalhos da artista goiana, Yara Pina, como em Instrução de ordem (2017-18) e Corpos sulcados (2019). Nesses dois trabalhos, a artista utiliza como gesto essencial, golpes com ferramentas em cima de sua sombra projetada na parede. Esses golpes violentos marcam uma silhueta da qual acaba constituindo uma inscrição no espaço, além de deixar no chão, os fragmentos da parede e dos materiais utilizados. A escolha dos materiais é

\footnotetext{
${ }^{3}$ A exposição Out of Actions: Between Performance and the Object, 1949-1979 ocorreu em 1998 no Museu de Arte Contemporânea de Los Angeles (MOCA). Com curadoria de Paul Schimmel, a exposição é considerada a primeira grande curadoria preocupada em examinar as relações dos objetos relacionados com a performance.
} 
de extrema importância para que ofereça a contextualização simbólica do tipo de violência que a artista quer atribuir. Instrução de ordem é realizado com instrumentos de uso da polícia como carabina e cassetetes, enquanto em Corpos sulcados, Yara Pina utiliza relha de arado para golpear a sua sombra. A partir do mesmo gesto, é desdobrado trabalhos diferentes que vão trazer tipos de violência diferentes, demonstrando desse modo, a importância das escolhas dos materiais diante de possibilidades simbólicas que estes podem apresentar.

Para a execução do trabalho, a artista sugere realizá-lo durante a montagem do espaço expositivo. Isso porque, Yara Pina não o compreende como uma performance, optando por não mostrar essa ação ao público. Mostrar os golpes violentos, evidencia uma imagem direta ao espectador, enquanto mostrar as marcas das silhuetas por esses mesmos golpes, deixa em suspensão a imagem desses gestos. A artista, portanto, acha que não cabe competir essas duas imagens (da ação e do vestígio) ${ }^{4}$, entendida às vezes como conflitantes. 0 que é importante pra ela, ou até mesmo potente, é sua silhueta desenhada com os golpes violentos mais do que sua ação, ou seja, a ausência de um corpo - tanto que Yara Pina opta e exige que na ficha técnica desses trabalhos sejam descritos como "vestígios de ação", justamente para entender que o que importa são os resquícios advindos de uma ação e não ela própria.

\footnotetext{
${ }^{4}$ Em entrevista com a artista, a mesma menciona que todas as ações são registradas com o interesse de documento pessoal, entretanto, esses vídeos gravados não são apresentados nos espaços expositivos.
} 


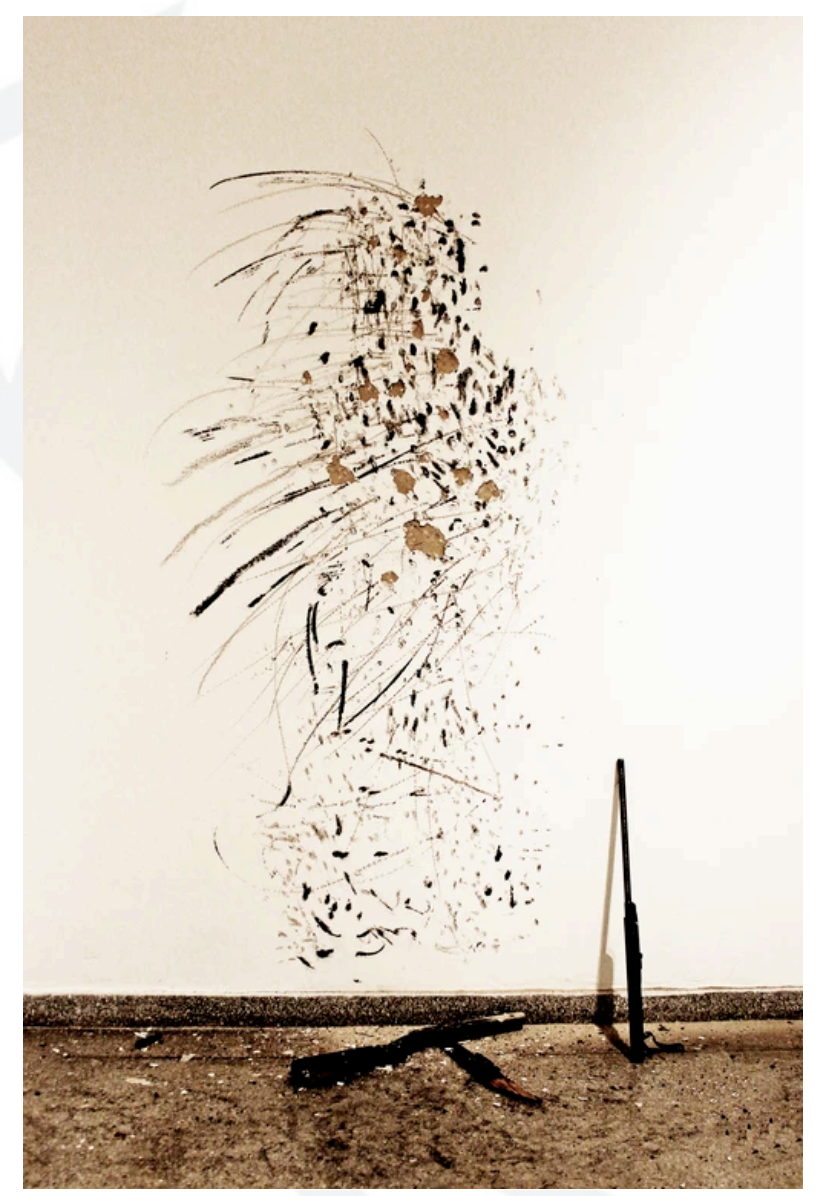

Figura 2: Yara Pina. Instrução de ordem \#1. Fonte: Acervo da artista.

Em muitos casos, é de se notar que a ação ou a temporalidade confere a qualidade de vestígio no objeto através da ficha técnica. A ficha técnica muitas vezes é responsável em descrever e contextualizar a ação. Em outro trabalho de Yara Pina intitulado Tosquiadas (2018), a artista anexa na ficha técnica as seguintes informações sobre os materiais utilizados: "faca oxidada por urina masculina, cabelo feminino".

Tosquiadas (2018), consiste em facas oxidadas com urina masculina e seu cabo feito com cabelos femininos, dispostas numa parede com as pontas para cima. Esses objetos, portanto, ganham o contexto de sua ação a partir da ficha técnica. Podemos notar que a ação está descrita na ficha técnica devido à 
necessidade de inserir um verbo dentro dos objetos, nesse caso o verbo "oxidar". A oxidação, esse elemento da ação, possui um significado de importância, justamente por estar relacionada com a parte mais fálica e violenta do objeto. Desse modo, fica evidente, à associação da violência de gênero exercida pelo masculino. A ação da urina que oxida a faca, nesse caso, não está visível somente na faca, mas na sua conjunção com o texto de parede sobre a obra que articula uma imagem violenta do corpo masculino, uma imagem silenciosa que é dada dentro de cada corpo observador.

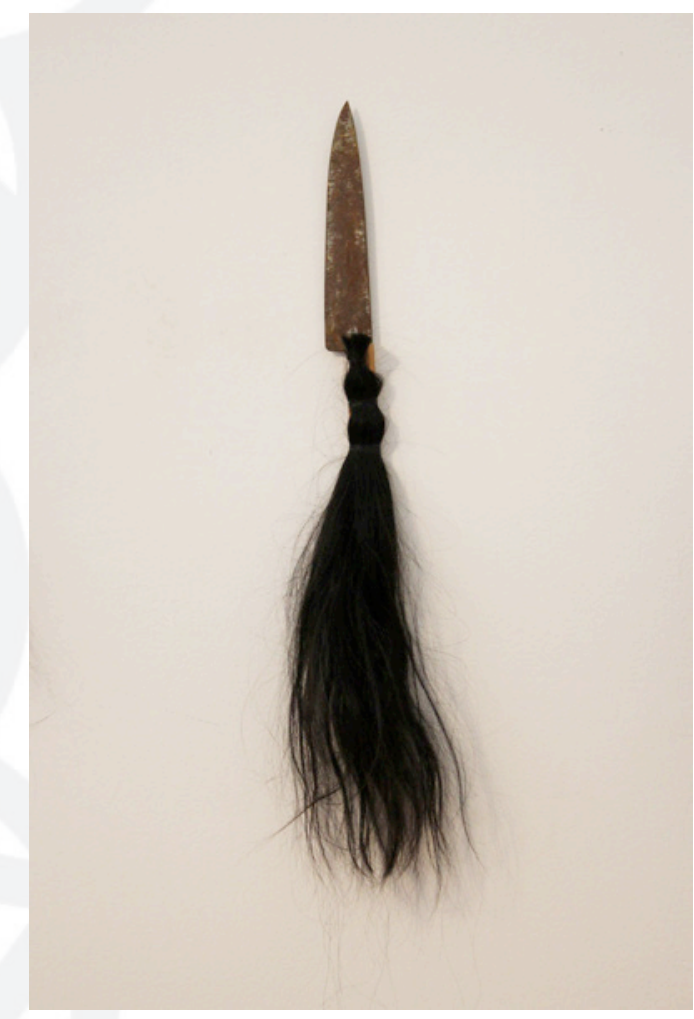

Figura 3. Yara Pina. Tosquiadas. Fonte: Acervo da artista

Pode-se estender as quantidades e diversidades de trabalhos relacionados às qualidades discutidas, entretanto, não é claro uma definição totalizante do que se entende como vestígio de ação, e também não existe um interesse em compreendê-lo por completo. $O$ interesse é entender as possibilidades nas 
formas de produção de imagem no que diz respeito à sua potencialidade, das quais muitas vezes escapam às formas comuns e evidentes. Muitas performances acabam gerando restos de materialidade das quais podem ampliar seus modos de apresentação, ou até mesmo de compreensão da proposta artística - nesse caso, a performance acaba ganhando dois momentos: o da ação, e do objeto que resta posteriormente. Seria o caso portanto, da responsabilidade da figura do(a) curador(a) em propor dentro do espaço e tempo da exposição, a articulação da presença desses vestígios após a performance, entendendo que esse vestígio pode se tornar uma importante ferramenta no que diz respeito às formas de apresentação e representação de uma imagem faltante.

\section{BIBLIOGRAFIA CITADA}

BHABHA, Homi K. O local da cultura. $2^{\text {a }}$ ed. Belo Horizonte: Editora UFMG, 2013.

DIDI-HUBERMAN, Georges. O que vemos, o que nos olha. 2a ed. São Paulo: Editora 34, 2010.

PALLAMIN, Vera. Aspectos da relação entre o estético e o político em Jacques Rancière. Risco Revista de Pesquisa em Arquitetura e Urbanismo, n. 12, p. 6-16, 1 jul. 2010.

RANCIÈRE, Jacques. A partilha do sensível: estética e política. $2^{\mathrm{a}}$ ed. São Paulo: Editora 34, 2009.

. $O$ desentendimento: política e filosofia. $2^{\mathrm{a}}$ ed. São Paulo: Editora 34, 2018.

. O destino das imagens. Rio de Janeiro: Contraponto, 2012a

. O espectador emancipado. São Paulo: WMF Martins Fontes, 2012b.

SAYRE, Henry M. The object of performance: The american avant-garde since 1970. Chicago: The University of Chicago Press, 1989. 
STILES, Kristine. Uncorrupted Joy: International Art Actions. In: SCHIMMEL, P; STILES, K (Org.). Out of Actions: Between Performance and the Object 1949-1979. Catálogo da exposição. New York: Thames and Hudson, 1998.

\section{Fontes eletrônicas}

Clara lanni. Disponível em: <http://claraianni.com/>. Acessado em 12 de setembro de 2019.

\section{LISTA DE FIGURAS}

\section{Lista de trabalhos}

Figura 1 - Clara lanni. Natureza Morta ou estudo para Ponto de Fuga, 2011. aço e perfurações de munições usadas pela Polícia Militar de São Paulo, SP. $35 \mathrm{~mm}, 38$ super, $40 \mathrm{~mm}, 22 \mathrm{~mm}$, festim 4.5, calibre 12.42, 12SG, calibre 12.50AE. $1 \mathrm{~m}$ x 2,5 m. Galeria Vermelho, São Paulo, Brasil. pág.: 105

Figura 2 - Yara Pina. Instrução de ordem \#1, 2017-18. Sombra agredida com golpes de carabina carbonizada. "vestígios de ação". pág.: 111

Figura 3 - Yara Pina. Tosquiadas, 2017. Facas oxidadas com urina masculina, cabelo feminino. Dimensões variadas. pág.: 112 